\title{
Simultaneous Determination of Carvedilol and Hydrochlorothiazide in Tablets and Spiked Human Plasma using Derivative Spectrophotometry
}

\author{
Aida Ansary ${ }^{1}$, Mona M. Abdel-Moety ${ }^{2 *}$, Fatma M. Abdel-Gawad ${ }^{2}$, Ether A. Mohamed ${ }^{2}$ and Motaza M. Khater \\ ${ }^{1}$ Chemistry Department, Faculty of Science, Cairo University, Giza, Egypt \\ ${ }^{2}$ National Organization for Drug Control and Research, Cairo, Egypt
}

\begin{abstract}
Quick and accurate methods for determination of carvedilol and hydrochlorothiazide in tablets and spiked human plasma by using third derivative $\left({ }^{3} D\right)$, fourth derivative $\left({ }^{4} D\right)$ and ratio spectra derivative $\left({ }^{1} D D\right)$ spectrophotometric methods were developed. The zero-crossing technique was employed in measurements, using ${ }^{3} D$ at 245.9 or $230.2 \mathrm{~nm}$ and ${ }^{4} \mathrm{D}$ at 247.4 or $226.9 \mathrm{~nm}$ for carvedilol or hydrochlorothiazide, respectively. The first-derivative of ratio spectra ( ${ }^{1} \mathrm{DD}$ ) where the amplitudes were measured at $236.1 \mathrm{~nm}$ for carvedilol and $261.1 \mathrm{~nm}$ for hydrochlorothiazide. The calibration curves were linear in the ranges of 1.0-20.0 $\mathrm{g} \mathrm{mL}^{-1}$ for each of carvedilol and hydrochlorothiazide using ${ }^{3} D^{4} \mathrm{D}$ and ${ }^{1} \mathrm{DD}$ methods. The suggested methods were tested using laboratory-prepared mixtures and were successfully applied for the analysis of pharmaceutical formulations. The methods retained their accuracy and precision when the standard addition technique was applied. The results obtained by applying the proposed methods were statistically analyzed and compared with those obtained by reported and official HPLC methods for carvedilol and hydrochlorothiazide, respectively.
\end{abstract}

These methods showed to be appropriate for simultaneous determination of carvedilol and hydrochlorothiazide in human plasma samples with a limit of quantitation (LOQ) is $\leq 0.5 \mu \mathrm{g} \mathrm{mL}-1$.

Keywords: Carvedilol; Hydrochlorothiazide; UV-derivative spectrophotometry; Ratio derivative spectrophotometry; Tablets; Spiked human plasma

\section{Introduction}

Carvedilol (CARV, Figure 1), 1-(9H-carbazol-4-yloxy)-3-[[2-(2methoxyphenoxy) ethyl]amino]-2-propanol, which is a nonselective $ß$-adrenergic blocker with a 1-blocking activity [1]. It is used in the treatment of sever heart failure, bradycardia and hypertension [2]. It is administered alone or together with antihypertensive, combined therapy of CARV and HCT had a significantly greater blood pressure reduction than with the same dosage of the drug alone [3].

Hydrochlorothiazide (HCT, Figure 1), 6-chloro-3,4-dihydro$2 \mathrm{H}-1,2,4$-benzothiadiazine-7-sulfonamide-1,1-dioxide, is a diuretic of the class of benzothiadiazines widely used in antihypertensive pharmaceutical formulations which decreases active sodium reabsorption and reduces peripheral vascular resistence [4].

Literature survey revealed that some RP-HPLC [5,6] and spectrophotometric methods [5,7] have been reported for estimation of CARV and HCT in combined formulations by first derivative spectrophotometry [5], dual wavelength analysis [7] and Q-analysis (graphical absorbance ratio) [7]. The first-order UV derivative spectrophotometric method [5] for the determination of the two mentioned drugs in synthetic mixture, it gave aberrant errors for the determination of CARV and a narrow linear dynamic range.

The carvedilol/hydrochlorothiazide mixture is not yet official

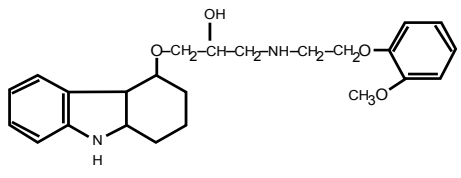

CARV<smiles>Cc1cc2c(cc1S(N)(=O)=O)S(=O)(=O)NCN2</smiles>

HCT
Figure 1: Chemical structures of CARV and HCT. in any pharmacopoeia. The purpose of the present study is to investigate the utility of third or fourth derivative and first derivative of ratio spectrophotometric methods in the assay of carvedilol and hydrochlorothiazide in combination in the pharmaceutical formulations without the necessity of sample treatment. A study concerning the simultaneous determination of these compounds in spiked human plasma samples using the suggested methods was also performed. The methods had sufficiently good accuracy, precision and permitted a simple, time- and money-saving assay of these compounds in mixtures.

\section{Experimental}

\section{Reagents and materials}

All chemicals and solvents used in this investigation were of analytical-reagent grade. Carvedilol (Roche, Milan, Italy) and hydrochlorothiazide (Arab Company for Gelatin and Pharmaceutical Products, Egypt) were of pharmaceutical grade. The following pharmaceutical preparations were purchased from commercial sources in the local market and subjected to analysis: Dilatrend tablets are labeled to contain $25 \mathrm{mg}$ CARV/tablet (Roche, Milan, Italy) and Co-dilatrol tablets are labeled to contain $25 \mathrm{mg}$ CARV and $12.5 \mathrm{mg}$ HCT/tablet (Chemipharma Pharmaceutical Industries, 6th october

*Corresponding author: Mona M. Abdel-Moety, National Organization for Drug Control and Research, P.O. Box 29, Analytical Chemistry Department, Cairo, Egypt, E-mail: Monaabdelmoety@Yahoo.Com

Received November 09, 2012; Accepted November 21, 2012; Published November 25, 2012

Citation: Ansary A, Abdel-Moety MM, Abdel-Gawad FM, Mohamed EA, Khater MM (2012) Simultaneous Determination of Carvedilol and Hydrochlorothiazide in Tablets and Spiked Human Plasma using Derivative Spectrophotometry. Pharmaceut Anal Acta 3:186. doi:10.4172/2153-2435.1000186

Copyright: ( 2012 Ansary A, et al. This is an open-access article distributed under the terms of the Creative Commons Attribution License, which permits unrestricted use, distribution, and reproduction in any medium, provided the original author and source are credited. 
Citation: Ansary A, Abdel-Moety MM, Abdel-Gawad FM, Mohamed EA, Khater MM (2012) Simultaneous Determination of Carvedilol and Hydrochlorothiazide in Tablets and Spiked Human Plasma using Derivative Spectrophotometry. Pharmaceut Anal Acta 3:186. doi:10.4172/2153-2435.1000186

Page 2 of 6

city, Cairo, Egypt). Human plasma sample was kindly supplied from Vacsera, Egypt.

\section{Preparation of stock and standard solutions}

Standard stock solutions each containing $1000 \mu \mathrm{g} \mathrm{mL} \mathrm{m}^{-1}$ of CARV and HCT were prepared separately in methanol. Working standard solutions of these drugs $\left(100 \mu \mathrm{g} \mathrm{mL}^{-1}\right)$ were obtained by dilution of the respective stock solution in methanol.

\section{Apparatus}

A Shimatzu 1601 PC double beam UV-visible spectrophotometer, with $1 \mathrm{~cm}$ quartz cuvettes, at a fixed slit width $(2 \mathrm{~nm})$, connected to an IBM-PC computer loaded with Shimatzu UVPC software was equipped with HP desk jet printer and used for all the absorbance measurements and treatment of data.

\section{General procedure}

Calibration graphs for third and fourth derivatives spectrophotometric methods: Aliquots of working standard solution $\left(100.0 \mu \mathrm{g} \mathrm{mL}^{-1}\right)$ were transferred into a series of $10 \mathrm{ml}$ volumetric flasks. For each drug $0.1-2.0 \mathrm{~mL}$ was taken and the volume was completed to the mark with methanol. The third derivative $\left({ }^{3} \mathrm{D}\right)$ and fourth derivative $\left({ }^{4} \mathrm{D}\right)$ spectra of the two series solutions for CARV and HCT were scanned within the range $220-320 \mathrm{~nm}$ against methanol as a blank. The values of the ${ }^{3} \mathrm{D}$ and ${ }^{4} \mathrm{D}$ amplitudes at 245.9 and $247.4 \mathrm{~nm}$, respectively (zero-crossing of HCT) were measured for the determination of CARV, while the amplitudes at 230.2 and $226.9 \mathrm{~nm}$, respectively, (zero-crossing of CARV) were recorded for the determination of HCT.

Under the experimental conditions described, standard calibration graphs for CARV and HCT (1.0-20.0 $\left.\mu \mathrm{g} \mathrm{mL}^{-1}\right)$ were constructed by plotting the ${ }^{3} \mathrm{D}$ and ${ }^{4} \mathrm{D}$ values versus concentration of drug and the regression equations were computed and recorded in table 1.

Calibration graphs for the first derivative of ratio spectra ( $\left.{ }^{1} \mathrm{DD}\right)$ : Aliquots from working solutions $\left(100 \mu \mathrm{g} \mathrm{mL}^{-1}\right)$ equivalent to $10-200 \mu \mathrm{g}$ of drug were transferred into separate $10-\mathrm{ml}$ volumetric flasks and the volume was completed to the mark with methanol (final concentration range $1.0-20.0 \mu \mathrm{g} \mathrm{mL}^{-1}$ of drug).

For CARV, each of the absorption spectrum was recorded and divided by the spectrum of HCT with a concentration $20 \mu \mathrm{g} \mathrm{mL}^{-1}$ as divisor. The first derivative of the ratio spectra $\left({ }^{1} \mathrm{DD}\right)$ were calculated with $\Delta \lambda=8 \mathrm{~nm}$ and scaling factor $(\mathrm{SF})=10$. The peak amplitudes

\begin{tabular}{|l|c|c|c|c|c|c|}
\hline \multirow{2}{*}{ Parameters } & \multicolumn{3}{|c|}{ CARV } & \multicolumn{3}{c|}{ HCT } \\
\cline { 2 - 7 } & ${ }^{3} \mathbf{D}$ & ${ }^{4} \mathbf{D}$ & ${ }^{1}$ DD & ${ }^{3} \mathbf{D}$ & ${ }^{4}$ D & ${ }^{1}$ DD \\
\hline Wavelength $(\mathrm{nm})$ & 245.9 & 247.4 & 236.1 & 230.2 & 226.9 & 261.1 \\
\hline Concentration range $\left(\mu \mathrm{g} \cdot \mathrm{mL}^{-1}\right)$ & \multicolumn{3}{|c|}{$1.0-20.0$} & \multicolumn{3}{c|}{$1.0-20.0$} \\
\hline Regression equation $(\mathrm{Y}) \mathrm{a}$ & & & & & & \\
\hline Slope $(\mathrm{b})$ & 0.090 & 0.066 & 1.044 & 0.103 & 0.066 & 1.313 \\
\hline Intercept $(\mathrm{a})$ & 0.028 & 0.014 & 0.013 & 0.033 & 0.024 & 0.017 \\
\hline Correlation coefficient $(\mathrm{r})$ & 0.9995 & 0.9999 & 0.9998 & 0.9998 & 0.9998 & 0.9999 \\
\hline Accuracy (mean\%, $\mathrm{n}=15)$ & 100.50 & 100.10 & 99.97 & 100.92 & 100.17 & 100.05 \\
\hline $\begin{array}{l}\text { Intraday precision } \\
\text { (RSD\%,n=12) }\end{array}$ & 0.53 & 0.49 & 0.85 & 0.68 & 0.70 & 0.93 \\
\hline $\begin{array}{l}\text { Interday precision } \\
\text { (RSD\%,n=12) }\end{array}$ & 0.62 & 0.78 & 0.57 & 0.87 & 0.66 & 0.71 \\
\hline LOD $\left(\mu \mathrm{g} \cdot \mathrm{mL}^{-1}\right)$ & 0.18 & 0.24 & 0.13 & 0.21 & 0.20 & 0.11 \\
\hline LOQ $\left(\mu \mathrm{gg} \cdot \mathrm{mL}^{-1}\right)$ & 0.55 & 0.94 & 0.39 & 0.64 & 0.61 & 0.33 \\
\hline
\end{tabular}

a $Y=a+b X$, where $Y$ is the amplitude and $X$ is the drug concentration.

Table 1: Analytical parameters for the calibration graphs $(n=7)$ for the determination of CARV and HCT using ${ }^{3} \mathrm{D},{ }^{4} \mathrm{D}$ and ${ }^{1} \mathrm{DD}$ methods. were measured at $236.1 \mathrm{~nm}$ and the values were plotted against the corresponding concentration of CARV and then the regression equation was obtained (Table 1).

For HCT, a similar procedure was followed with a concentration of $20 \mu \mathrm{gLL}^{-1}$ CARV as a divisor. HCT was determined by measuring the amplitude value of the ratio spectra at $261.1 \mathrm{~nm}$ with $\Delta \lambda=8 \mathrm{~nm}$ and SF $=100$. The calibration graph was plotted representing the concentration versus the ${ }^{1} \mathrm{DD}$ amplitude and the regression equation was computed and recorded in table 1 .

Procedure for tablets: Ten tablets were weighed, finely powdered and mixed thoroughly. An accurately weighed amount of powder equivalent to $100 \mathrm{mg}$ of CARV and $50 \mathrm{mg}$ of HCT was individually transferred into a $100 \mathrm{~mL}$ volumetric flask, diluted with methanol, shaked for about $10 \mathrm{~min}$ and then completed to volume with methanol. This solution was filtered to separate any insoluble matter, and the filtrate was collected in a clean flask. After filtration, working solutions were prepared by taking suitable aliquots of clear filtrate and diluted with methanol. The assay was completed as described under General procedures. The contents of CARV and HCT were calculated from the corresponding regression equation.

Procedure for spiked human plasma: A liquots of $1.0 \mathrm{~mL}$ of human plasma were spiked with different concentration levels of CARV and HCT (20.0-800 $\mu \mathrm{g}$ for both drugs) and transferred into centrifugation tubes, then completed with methanol to volume of $4 \mathrm{~mL}$. Mix well and leave for $2 \mathrm{~min}$ to be sure of complete deproteinization of the plasma. The solutions were centrifuged at $3000 \mathrm{rpm}$ for $30 \mathrm{~min}$. One milliliter of each of the clear supernatant solution was withdrawn and transferred into a series of $10-\mathrm{mL}$ volumetric flask, then the volume was completed with methanol. The final concentration range of 0.5-20.0 $\mu \mathrm{g}$ $\mathrm{mL}^{-1}$ was obtained for both drugs. Then ${ }^{3} \mathrm{D},{ }^{4} \mathrm{D}$ and ${ }^{1} \mathrm{DD}$ methods were applied for the determination of CARV and HCT in spiked human plasma at their selected wavelengths. A blank experiment was carried out simultaneously. The nominal content of each drug in plasma was determined by using the corresponding regression equation.

\section{Results and Discussion}

Development of simple, rapid, sensitive and accurate analytical methods for routine quantitative determination of samples will reduce unnecessary tedious sample preparations, cost materials and laboratories. UV-spectrophotometric methods of analysis offer cost effective and time saving alternative to HPLC method of analysis [8].

Zero-order absorption spectra of CARV and HCT (Figure 2) show strong spectral overlap, which interfere with direct spectrophtometric analysis of the studied drugs. The suggested

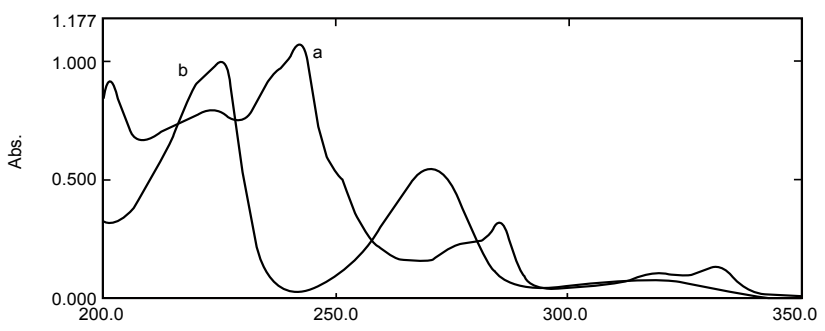

Figure 2: Zero-order absorption spectra for $8.0 \mu \mathrm{g} \cdot \mathrm{mL}^{-1}$ of both (a) CARV and (b) HCT in methanol. 
Citation: Ansary A, Abdel-Moety MM, Abdel-Gawad FM, Mohamed EA, Khater MM (2012) Simultaneous Determination of Carvedilol and Hydrochlorothiazide in Tablets and Spiked Human Plasma using Derivative Spectrophotometry. Pharmaceut Anal Acta 3:186. doi:10.4172/2153-2435.1000186

derivative spectrophotometric methods provide simple, convenient and accurate methods for simultaneous analysis of CAR and HCT in their combined dosage forms without derivatization procedure.

The main step in the development and validation of an analytical method of analysis is to improve the conditions and parameters, which should be followed in the development and validation [9]. Different solvents were studied: methanol, ethanol, acetonitrile, water, $0.1 \mathrm{M}$ $\mathrm{HCl}$ and $0.1 \mathrm{M} \mathrm{NaOH}$, to develop suitable methods of analysis. From solvent effect studies and spectral behaviors of CARV and HCT, methanol was selected as a solvent for the ${ }^{3} \mathrm{D},{ }^{4} \mathrm{D}$ and ${ }^{1} \mathrm{DD}$ methods.

\section{Derivative UV- spectrophotometry}

The fundamental principles and convention of derivative spectrophotometry have been enounced in the works of O'Haver and Green [10] and Fell and Smith [11]. The more convenient order of derivative and working wavelengths were selected by preliminary tests. The basic requirements of the present procedure were that neither shape of derivative spectra nor locations of the zero-crossing wavelengths were dependent on the composition of binary mixtures.

First to fourth derivative spectra of methanolic solutions of CAVR and HCT at appropriate concentrations were taken and observed. The good resolution of the derivative spectra allowed to select the optimal working wavelengths from several zero-crossing wavelengths, i.e., those which exhibited the best linear response to analyte concentration and/or higher sensitivity.

Third and fourth UV derivative spectra of methanolic drug solutions were the best since the derivative absorbance peaks of these drugs were isolated in these spectra (Figures 3-6). Zero-crossing wavelengths at 245.9 or $247.4 \mathrm{~nm}$ for CARV and at 230.2 or $226.9 \mathrm{~nm}$ for HCT determinations in case of ${ }^{3} \mathrm{D}$ or ${ }^{4} \mathrm{D}$ methods, respectively, were selected since reproducible readings were obtained at these wavelengths. Linear relationships between derivative amplitude and drug concentration were obtained over the concentration range 1.0-20.0 $\mathrm{g} \mathrm{mL} \mathrm{m}^{-1}$ for both drugs. The regression equations were computed and listed in table 1.

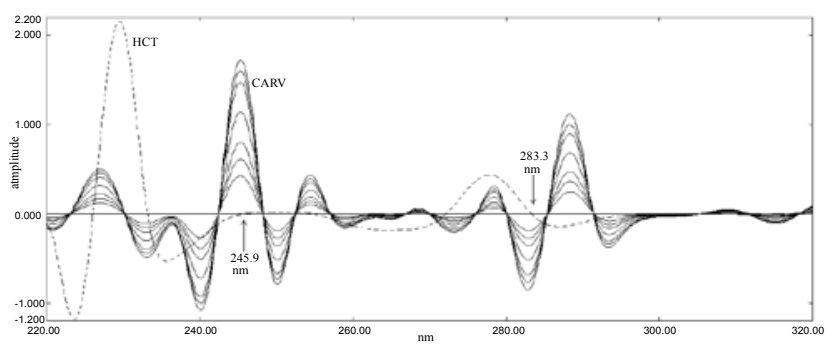

Figure 3: Third derivative spectra $\left({ }^{3} \mathrm{D}\right)$ for CARV $\left(1.0-20.0 \mu \mathrm{g} \cdot \mathrm{mL}^{-1}\right)$ in methanol.

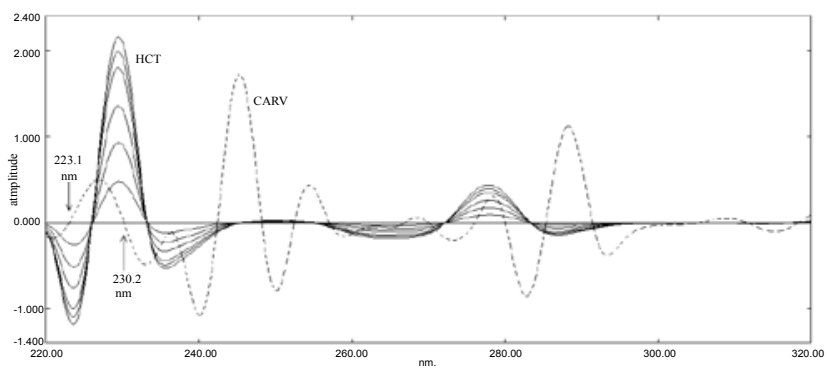

Figure 4: Third derivative spectra $\left({ }^{3} \mathrm{D}\right)$ for CARV $\left(1.0-20.0 \mu \mathrm{g} \cdot \mathrm{mL}^{-1}\right)$ in methanol.

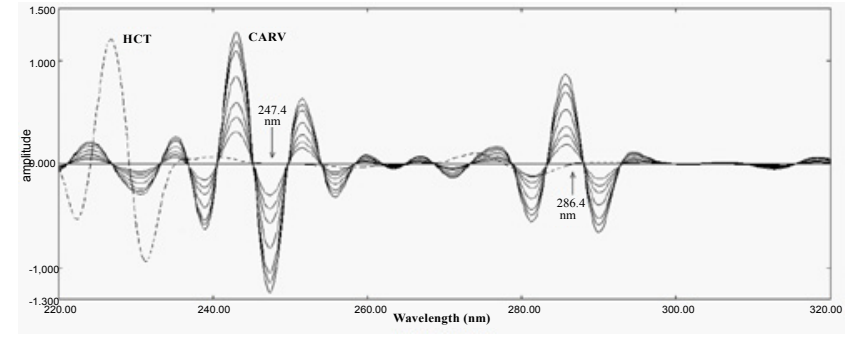

Figure 5: Fourth derivative spectra $\left({ }^{4} \mathrm{D}\right)$ for CARV $\left(1.0-20.0 \mu \mathrm{g} \cdot \mathrm{mL}^{-1}\right)$ in methanol.

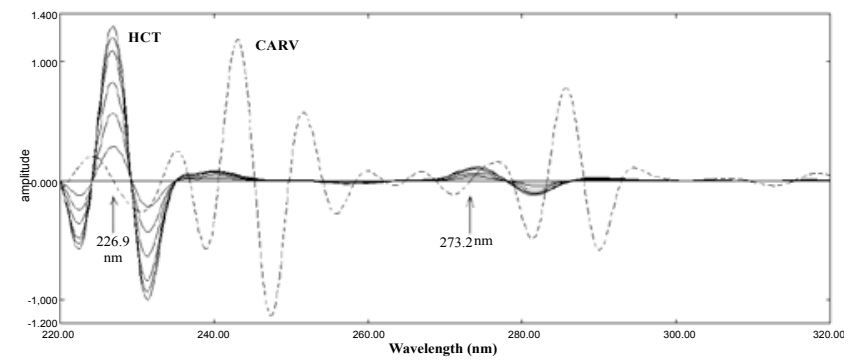

Figure 6: Fourth derivative spectra $\left({ }^{4} \mathrm{D}\right)$ for $\mathrm{HCT}\left(1.0-20.0 \mu \mathrm{g} \cdot \mathrm{mL}^{-1}\right)$ in methanol.

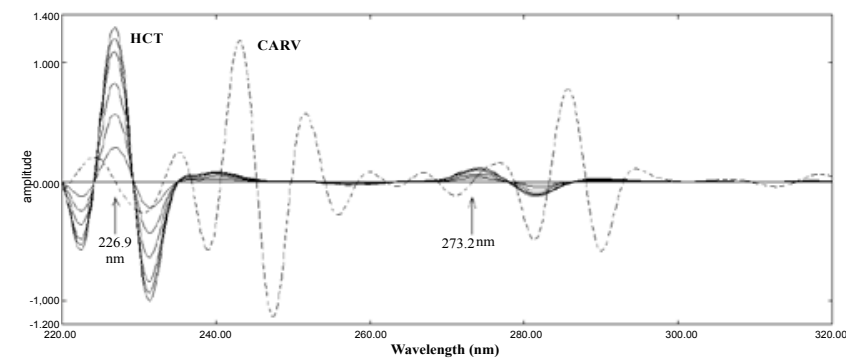

Figure 7: First derivative of ratio spectra ('DD) of CARV $\left(1.0-20.0 \mu \mathrm{g} \cdot \mathrm{mL}^{-1}\right)$ using $20.0 \mu \mathrm{g} \cdot \mathrm{mL}^{-1} \mathrm{HCT}$ as divisor in methanol at $\Delta \lambda=8 \mathrm{~nm}$ and $\mathrm{SF}=10$.

\section{Ratio-spectra method}

To optimize the simultaneous determination of CARV and HCT by using ${ }^{1} \mathrm{DD}$ method, it is necessary to test the influence of the variables: divisor standard concentration, $\Delta \lambda$ and scaling factor (SF). All these variables were studied. From several tests for correct choice of the divisor standard concentration, the best results in terms of signal to noise ratio, sensitivity and repeatability and validity range of Beer's law were tested.

For method ${ }^{1} \mathrm{DD}$, a standard spectrum of $20 \mu \mathrm{g} \mathrm{mL} \mathrm{L}^{-1}$ for both HCT and CARV was considered as a suitable divisor concentration for the determination of the two drugs in a mixture. The absorption spectra of the mixtures prepared at different concentrations of CARV and HCT were recorded in the range $220-320 \mathrm{~nm}$ and stored in the IBM-PC. The stored spectra of the binary mixtures, CARV and HCT were divided by a standard spectrum of $20 \mu \mathrm{g} \mathrm{mL}^{-1} \mathrm{HCT}$. The ratio spectra were smoothed with $\Delta \lambda=8 \mathrm{~nm}$ and $\mathrm{SF}=10$ and their derivatives were traced with the same $\Delta \lambda$ (Figure 7 ). In the binary mixtures, the concentration of CARV was determined by measuring the amplitude at $236.1 \mathrm{~nm}$ corresponding to maximum wavelength.

For the determination of HCT, the stored spectra of the mixtures 
Citation: Ansary A, Abdel-Moety MM, Abdel-Gawad FM, Mohamed EA, Khater MM (2012) Simultaneous Determination of Carvedilol and Hydrochlorothiazide in Tablets and Spiked Human Plasma using Derivative Spectrophotometry. Pharmaceut Anal Acta 3:186. doi:10.4172/2153-2435.1000186

Page 4 of 6

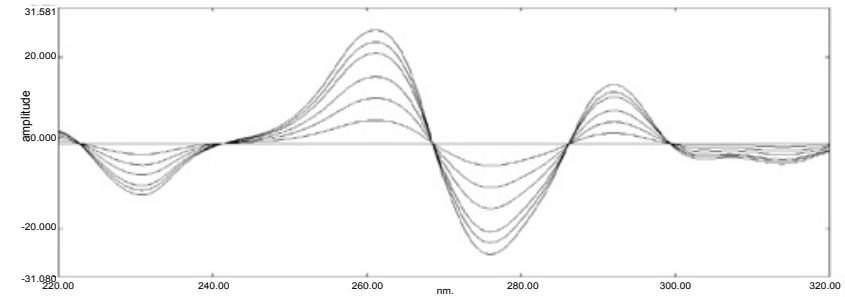

Figure 8: First derivative of ratio spectra ('DD) of HCT (1.0- $\left.20.0 \mu \mathrm{g} \cdot \mathrm{mL}^{-1}\right)$ using $20.0 \mu \mathrm{g} \cdot \mathrm{mL}^{-1} \mathrm{CARV}$ as divisor in methanol at $\Delta \lambda=8 \mathrm{~nm}$ and $\mathrm{SF}=100$.

\begin{tabular}{|c|c|c|c|c|c|c|c|}
\hline \multicolumn{8}{|c|}{ Recovery (\%)a } \\
\hline & \multicolumn{3}{|c|}{ CARV } & \multicolumn{3}{|c|}{ HCT } & \\
\hline \multicolumn{2}{|l|}{ Method } & ${ }^{3} \mathrm{D}$ & ${ }^{4} \mathrm{D}$ & ${ }^{1} \mathrm{DD}$ & ${ }^{3} \mathrm{D}$ & ${ }^{4} \mathrm{D}$ & ${ }^{1} \mathrm{DD}$ \\
\hline \multicolumn{2}{|c|}{ Wavelength $(\mathrm{nm})$} & 245.9 & 247.4 & 236.1 & 230.2 & 226.9 & 261.1 \\
\hline \multicolumn{2}{|c|}{ Added $\left(\mu \mathrm{g} \cdot \mathrm{mL}^{-1}\right)$} & & & & & & \\
\hline CARV & $\mathrm{HCT}$ & & & & & & \\
\hline 8.0 & 2.0 & 100.00 & 99.50 & 100.01 & 99.32 & 99.75 & 101.05 \\
\hline 8.0 & 4.0 & 101.87 & 99.73 & 101.05 & 101.17 & 100.15 & 100.08 \\
\hline 8.0 & 6.0 & 100.90 & 100.75 & 102.00 & 100.87 & 101.07 & 101.12 \\
\hline 8.0 & 8.0 & 100.00 & 100.01 & 101.02 & 101.60 & 100.40 & 100.09 \\
\hline 12.0 & 10.0 & 99.47 & 99.90 & 99.89 & 100.33 & 99.37 & 102.00 \\
\hline 14.0 & 10.0 & 99.68 & 100.02 & 99.97 & 99.92 & 99.58 & 100.06 \\
\hline 16.0 & 10.0 & 100.44 & 99.80 & 100.30 & 99.70 & 100.03 & 99.63 \\
\hline 18.0 & 10.0 & 99.76 & 99.54 & 99.61 & 100.04 & 100.11 & 99.89 \\
\hline \multicolumn{2}{|c|}{ Mean recovery (\%) } & 100.26 & 99.91 & 100.48 & 100.37 & 100.06 & 100.49 \\
\hline \multicolumn{2}{|l|}{ RSD\% } & 0.79 & 0.39 & 0.81 & 0.78 & 0.53 & 0.81 \\
\hline
\end{tabular}

a Mean of three independent analyses

Table 2: Determination of carvedilol (CARV) and hydrochlorothiazide (HCT) in laboratory prepared mixtures using ${ }^{3} \mathrm{D},{ }^{4} \mathrm{D}$, and ${ }^{1} \mathrm{DD}$ methods.

are divided by $20 \mu \mathrm{g} \mathrm{mL}^{-1}$ of CARV; Figure 8 shows the first derivative of the ratio spectra $\left({ }^{1} \mathrm{DD}\right)$ plotted with the intervals of $\Delta \lambda=8 \mathrm{~nm}$ and $\mathrm{SF}=100$. The contents of HCT in binary mixtures were determined by measuring the amplitudes at $261.1 \mathrm{~nm}$ corresponding to maximum wavelength. The calibration graphs at 236.1 and $261.1 \mathrm{~nm}$ for CARV and HCT, respectively, were obtained by plotting the values of the first derivative of ratio spectra CARV/HCT and HCT/CARV, with variable concentrations of CARV and HCT, respectively. The proposed method is applicable over the concentration range $1.0-20.0 \mu \mathrm{g} \mathrm{mL}^{-1}$ for both CARV and HCT and the regression equations were computed and grouped in table 1 .

Statistical analysis of the data shows that the slope of the calibration graph for each drug was independent on the concentration of the other component of the mixture. This means that the ${ }^{3} \mathrm{D},{ }^{4} \mathrm{D}$, and ${ }^{1} \mathrm{DD}$ amplitudes of the mixture were only a function of the concentration of the drug at the specified wavelength.

\section{Methods validation}

Methods validation has been performed as per the International Conference on Harmonization (ICH), guidelines [12].

Linearity: The linearity of the developed methods was evaluated by analyzing different concentrations of standard solutions of CARV and HCT in triplicates for ${ }^{3} \mathrm{D},{ }^{4} \mathrm{D}$ and ${ }^{1} \mathrm{DD}$ methods. Beer's law concentration range was found to be $1.0-20.0 \mu \mathrm{g} \mathrm{mL}^{-1}$ for both CARV and HCT. The values of correlation coefficients were close to unity indicating good linearity. The characteristic parameters for the constructed equations are summarized in table 1 .

Accuracy: The previously mentioned methods were repeated five times for three different concentrations of pure samples. The concentrations were calculated each time from its corresponding regression equation. The mean recovery percentages are found to be $100.50,100.10$ and $99.97 \%$ for CARV and 100.92, 100.17 and $100.05 \%$ for HCT using ${ }^{3} \mathrm{D},{ }^{4} \mathrm{D}$ and ${ }^{1} \mathrm{DD}$ methods, respectively, (Table 1 ). The excellent recoveries obtained suggest the good accuracy of the proposed methods.

Precision: To measure the degree of method repeatability (intraday precision), three different concentrations (within linearity range) were freshly prepared and analyzed, each three times within the same day and in three successive days (interday precision). The results listed in table 1 , show that no significant difference for the assay, which tested within-day (repeatability) and between-day (reproducibility). The RSD values were less than $1 \%$ indicating high degree of precision of the proposed methods.

Selectivity: Method selectivity for each drug in presence of the other was achieved by preparing different mixtures of drugs within linearity range. The results obtained in Table 2 are good indication of the high selectivity of the three methods and their potential for the simultaneous determination of CARV and HCT from their mixtures.

limits of detection (LOD) and quantitation (LOQ): According to ICH recommendation [12] the approach based on SD of the response and the slope of Beer's law (b) was used for determination of the detection and quantitation limits in accordance to the following equations: $\mathrm{LOD}=3.3 \times \mathrm{SD} / \mathrm{b}$ and $\mathrm{LOQ}=10 \times \mathrm{SD} / \mathrm{b}$. Results presented in table 1 , indicate the methods are sensitive for determination of the studied drugs.

Standard addition method: Standard addition technique was applied to analysis of the commercial tablets (Dilatrend and Codilatrol tablets) by adding knows amounts of pure drug to a known concentration of preanalyzed tablets at three different levels (50\%, 75\% and $100 \%)$. The concentration of the pure drug was calculated from the corresponding regression equation of CARV and HCT. The recovery results in Table 3 illustrate the suitability of the methods for the analysis of CARV and HCT in their dosage forms without interference from the common excipients.

Application to tablets: The proposed methods were applied for the determination of CARV and HCT in bulk powder and commercial tablets of Dilatrend (for CARV) and Co-dilatrol (for both CARV and HCT) (Table 4). Five replicate determinations were made. Satisfactory results were obtained for CARV and HCT and were in good agreement with label claims. The results of CARV and HCT were compared with those obtained by the HPLC methods $[5,13,14]$, using t-and F-tests. The values at $95 \%$ confidence limit did not exceed the theoretical values of 2.306 and 6.39 for $\mathrm{t}$-and F-tests, respectively, indicate no significant difference between the performance of these methods regarding accuracy and precision (Table 4).

Application to spiked human plasma: In this part, the ${ }^{3} \mathrm{D},{ }^{4} \mathrm{D}$ and ${ }^{1} \mathrm{DD}$ derivative spectrophotometric methods were used for the determination of CARV and HCT in spiked human plasma due to their selected analytical signals are highly sensitive and well defined and so they are possible to expect more accurate results. The mean advantage of the use of these methods for the direct determinations of drugs in human plasma is their ability to eliminate the background absorption of the matrix and avoids the need of a preliminary clean-up stage [15].

The validity of the methods was proved for analysis ICH guideline [12] (linearity, accuracy, precision, LOD and LOQ). The results are 
Citation: Ansary A, Abdel-Moety MM, Abdel-Gawad FM, Mohamed EA, Khater MM (2012) Simultaneous Determination of Carvedilol and Hydrochlorothiazide in Tablets and Spiked Human Plasma using Derivative Spectrophotometry. Pharmaceut Anal Acta 3:186. doi:10.4172/2153-2435.1000186

Page 5 of 6

\begin{tabular}{|c|c|c|c|c|c|c|}
\hline \multirow[t]{2}{*}{ Method } & \multicolumn{2}{|c|}{ Amount, $\mu \mathrm{g} \cdot \mathrm{mL}^{-1}$} & \multicolumn{2}{|c|}{ Carvedilol (CARV) } & \multicolumn{2}{|c|}{ Hydrochlorothiazide (HCT) } \\
\hline & Taken & Added & Found $\pm \mathrm{RSDa}$ & Recovery \pm RSD (\%) & Found $\pm \mathrm{RSDa}$ & Recovery \pm RSD (\%) \\
\hline \multirow[t]{5}{*}{${ }^{3} \mathrm{D}$} & & & \multicolumn{2}{|r|}{$245.9 \mathrm{~nm}$} & \multicolumn{2}{|r|}{$230.2 \mathrm{~nm}$} \\
\hline & 10.0 & 5.0 & $4.94 \pm 0.05$ & $98.80 \pm 1.01$ & $4.99 \pm 0.04$ & $99.80 \pm 0.80$ \\
\hline & 10.0 & 7.5 & $7.60 \pm 0.6$ & $101.33 \pm 0.79$ & $7.48 \pm 0.03$ & $99.73 \pm 0.40$ \\
\hline & 10.0 & 10.0 & $9.97 \pm 0.09$ & $99.70 \pm 0.90$ & $10.05 \pm 0.06$ & $100.50 \pm 0.60$ \\
\hline & \multicolumn{2}{|c|}{ Mean \pm RSD(\%) } & & $99.94 \pm 0.90$ & & $100.01 \pm 0.60$ \\
\hline${ }^{4} \mathrm{D}$ & & & \multicolumn{2}{|r|}{$247.4 \mathrm{~nm}$} & \multicolumn{2}{|r|}{$226.9 \mathrm{~nm}$} \\
\hline & 10.0 & 5.0 & $5.02 \pm 0.04$ & $100.40 \pm 0.80$ & $4.97 \pm 0.05$ & $99.40 \pm 1.101$ \\
\hline & 10.0 & 7.5 & $7.47 \pm 0.05$ & $99.60 \pm 0.67$ & $7.55 \pm 0.04$ & $100.66 \pm 0.53$ \\
\hline & 10.0 & 10.0 & $10.03 \pm 0.09$ & $100.30 \pm 0.90$ & $9.95 \pm 0.07$ & $99.50 \pm 0.70$ \\
\hline & \multicolumn{2}{|c|}{ Mean $\pm \mathrm{RSD}(\%)$} & & $100.10 \pm 0.79$ & & $99.85 \pm 0.75$ \\
\hline${ }^{1} \mathrm{DD}$ & & & \multicolumn{2}{|r|}{$236.1 \mathrm{~nm}$} & \multicolumn{2}{|r|}{$261.1 \mathrm{~nm}$} \\
\hline & 10.0 & 5.0 & $4.98 \pm 0.03$ & $99.60 \pm 0.60$ & $5.02 \pm 0.02$ & $100.40 \pm 0.40$ \\
\hline & 10.0 & 7.5 & $7.51 \pm 0.04$ & $100.13 \pm 0.53$ & $7.49 \pm 0.05$ & $99.87 \pm 0.67$ \\
\hline & 10.0 & 10.0 & $9.99 \pm 0.07$ & $99.90 \pm 0.70$ & $10.02 \pm 0.08$ & $100.20 \pm 0.80$ \\
\hline & \multicolumn{2}{|c|}{ Mean \pm RSD(\%) } & & $99.88 \pm 0.61$ & & $100.16 \pm 0.62$ \\
\hline
\end{tabular}

a Mean of five independent analyses.

Table 3: Recovery data by standard addition method for CARV and HCT in drug formulation (Co-dilatrol tablets).

\begin{tabular}{|c|c|c|c|c|c|}
\hline \multirow[t]{2}{*}{ Sample } & \multirow[t]{2}{*}{ Test $(n=5)$} & \multicolumn{4}{|c|}{ Method } \\
\hline & & ${ }^{3} \mathrm{D}$ & ${ }^{4} \mathrm{D}$ & ${ }^{1} \mathrm{DD}$ & HPLC \\
\hline \multicolumn{2}{|l|}{ Carvedilol (CARV) } & $(245.9 \mathrm{~nm})$ & $(247.4 \mathrm{~nm})$ & $(236.1 \mathrm{~nm})$ & \\
\hline \multirow[t]{3}{*}{ Bulk power } & Mean \pm RSD (\%) & $100.39 \pm 0.93$ & $100.27 \pm 0.77$ & $100.50 \pm 0.81$ & $100.90 \pm 0.69^{a}$ \\
\hline & $\mathrm{t}$ & 0.98 & 1.36 & 0.84 & $(2.306)^{d}$ \\
\hline & $\mathrm{F}$ & 1.82 & 1.25 & 1.38 & $(6.39)^{d}$ \\
\hline \multirow[t]{3}{*}{ Dilatrend tablets } & Mean \pm RSD (\%) & $99.85 \pm 0.62$ & $99.93 \pm 0.63$ & $99.90 \pm 0.51$ & $99.66 \pm 0.72^{a}$ \\
\hline & $\mathrm{t}$ & 0.42 & 0.40 & 0.60 & \\
\hline & $\mathrm{F}$ & 1.37 & 1.30 & 2.07 & \\
\hline \multirow[t]{3}{*}{ Co-dilatrol tablets } & Mean \pm RSD (\%) & $99.91 \pm 0.51$ & $99.96 \pm 0.48$ & $99.93 \pm 0.53$ & $99.89 \pm 0.70^{b}$ \\
\hline & $\mathrm{t}$ & 0.05 & 0.18 & 0.18 & \\
\hline & $\mathrm{F}$ & 1.88 & 2.13 & 1.74 & \\
\hline \multicolumn{2}{|c|}{ Hydrochlorothiazide (HCT) } & $(230.2 \mathrm{~nm})$ & $(226.9 \mathrm{~nm})$ & $(261.1 \mathrm{~nm})$ & \\
\hline \multirow[t]{3}{*}{ Bulk power } & Mean \pm RSD(\%) & $99.85 \pm 0.70$ & $100.28 \pm 0.94$ & $100.57 \pm 0.84$ & $99.93 \pm 0.68^{c}$ \\
\hline & $\mathrm{t}$ & 0.18 & 0.67 & 1.32 & \\
\hline & $\mathrm{F}$ & 1.06 & 1.91 & 1.53 & \\
\hline Co-dilatrol & Mean \pm RSD (\%) & $99.90 \pm 0.72$ & $99.85 \pm 0.61$ & $99.97 \pm 0.80$ & $99.72 \pm 0.96^{b}$ \\
\hline \multirow[t]{2}{*}{ tablets } & $t$ & 0.34 & 0.26 & 0.45 & \\
\hline & $\mathrm{F}$ & 1.77 & 2.49 & 1.44 & \\
\hline
\end{tabular}

a Reference no. [13].

${ }^{b}$ Reference no. [5]

c The United States Pharmacopoeia 2009 [14]

d Theoretical values of $\mathrm{t}-$ and F- tests at $95 \%$ confidence level.

Table 4: Results of the determination of CARV and HTC using ${ }^{3} \mathrm{D},{ }^{4} \mathrm{D},{ }^{1} \mathrm{DD}$ and HPLC methods in bulk power and in commercial tablets.

abridged in table 5. The high sensitivity of the proposed methods allowed the determination of CARV and HCT in spiked human plasma.

Under the experimental condition, calibration curves in plasma were obeyed in the concentration range of $0.5-20.0 \mu \mathrm{g} \mathrm{mL}^{-1}$ at 245.9, 247.4 and $236.1 \mathrm{~nm}$ for CARV and $0.5-18.0 \mu \mathrm{g} \mathrm{mL}^{-1}$ at $230.2,226.9$ and $261.1 \mathrm{~nm}$ for HCT, using ${ }^{3} \mathrm{D},{ }^{4} \mathrm{D},{ }^{1} \mathrm{DD}$ methods, respectively. The correlation coefficients were between 0.9996-0.9998; indicate good linearity of the present methods.

The accuracy of the proposed methods were determined by investigating the percentage recovery of spiked human plasma solutions with four concentration levels, each in triplicate, ranging from 4.0-16.0 $\mu \mathrm{gL}^{-1}$ for both CARV and HCT. The percentage recoveries are 97.2399.25\% for CARV and 97.13-98.52\% for HCT (Table 5), which indicate good accuracy of the proposed methods.

For precision study, intraday precision (repeatability) was evaluated by assaying freshly prepared solutions of plasma spiked with different concentrations of CARV and HCT (4.0-16.0 $\mu \mathrm{g} \mathrm{mL}^{-1}$ for both drugs) in triplicate within the same day and in three successive days (interday precision). The results are listed in table 5 and showed RSD values are less than $1 \%$ which indicates high degree of precision of the proposed methods.

From the above studies, the use UV derivative spectra allows the direct determination of CARV and HCT in spiked human plasma at the $\mu \mathrm{g} \mathrm{mL}^{-1}$ level without any extraction or separation step. These methods avoid the matrix effects that occur at wavelength higher than $300 \mathrm{~nm}$. In this region the endogenous components of blood plasma interfere significantly in the fundamental absorption spectra but not in the higher order derivative spectra [15]. Following oral administration of a $25 \mathrm{mg}$ CARV tablet, maximum plasma concentrations were 5 to $99 \mu \mathrm{g} \mathrm{ml}^{-1}$ (mean $21 \mu \mathrm{g} \mathrm{ml}^{-1}$ ) see after $1.46 \mathrm{~h} \mathrm{[16],} \mathrm{i.e.} \mathrm{its} \mathrm{concentration}$ in plasma is in the upper limits of concentration range of the proposed 
Citation: Ansary A, Abdel-Moety MM, Abdel-Gawad FM, Mohamed EA, Khater MM (2012) Simultaneous Determination of Carvedilol and Hydrochlorothiazide in Tablets and Spiked Human Plasma using Derivative Spectrophotometry. Pharmaceut Anal Acta 3:186. doi:10.4172/2153-2435.1000186

\begin{tabular}{|c|c|c|c|c|c|c|}
\hline Parameter & CARV & & & HCT & & \\
\hline & ${ }^{3} \mathbf{D}$ & ${ }^{4} \mathrm{D}$ & ${ }^{1} \mathrm{DD}$ & ${ }^{3} \mathbf{D}$ & ${ }^{4} \mathbf{D}$ & ${ }^{1} \mathrm{DD}$ \\
\hline Wavelength (nm) & 245.9 & 247.4 & 236.1 & 230.2 & 226.9 & 261.1 \\
\hline Concentration range $\left(\mu \mathrm{g} \cdot \mathrm{mL}^{-1}\right)$ & \multicolumn{3}{|c|}{$0.5-20.0$} & \multicolumn{3}{|c|}{$0.5-18.0$} \\
\hline \multicolumn{7}{|l|}{ Regression equation $(\mathrm{Y})^{\mathrm{a}}$} \\
\hline Slope (b) & 0.084 & 0.064 & 1.326 & 0.027 & 0.017 & 1.030 \\
\hline Intercept (a) & 0.019 & 0.020 & 0.080 & 0.006 & 0.004 & 0.099 \\
\hline Correlation coefficient $(r)$ & 0.9996 & 0.9997 & 0.9998 & 0.9996 & 0.9996 & 0.9997 \\
\hline Accuracy (mean\%, n=12) & 97.23 & 99.25 & 98.32 & 97.50 & 97.13 & 98.52 \\
\hline Intraday precision $(\mathrm{RSD} \%, \mathrm{n}=12)$ & 0.50 & 0.48 & 0.57 & 0.37 & 0.36 & 0.49 \\
\hline Interday precision $(\mathrm{RSD} \%, \mathrm{n}=12)$ & 0.53 & 0.40 & 0.53 & 0.42 & 0.54 & 0.56 \\
\hline LOD $\left(\mu \mathrm{g} \cdot \mathrm{mL}^{-1}\right)$ & 0.15 & 0.16 & 0.13 & 0.16 & 0.14 & 0.11 \\
\hline $\mathrm{LOQ}\left(\mu \mathrm{g} \cdot \mathrm{mL}^{-1}\right)$ & 0.45 & 0.48 & 0.39 & 0.48 & 0.42 & 0.33 \\
\hline
\end{tabular}

systemic hypertension. Am J Cardiol 59: 400-405.

3. Radevski IV, Valtchanova SP, Candy GP, Tshele EF, Sareli P (1999) Comparison of acebutolol with and without hydrochlorothiazide versus carvedilol with and without hydrochlorothiazide in black patients with mild to moderate systemic hypertension. Am J Cardiol 84: 70-75

4. The Merck Index (2001) An Encyclopedia of Chemicals, Drugs and Biologicals (13th edn), Merck, USA 1692.

5. Sultan M (2008) Simultaneous determination of carvedilol and hydrochlorothiazide in tablets by derivative spectrophotometric and highperformance liquid chromatographic methods. Asian J Chem 20: 2283-2292.

6. Haggag RS, Shaalan RA, Belal TS (2010) Validated HPLC determination of the two fixed dose combinations (chlordiazepoxide hydrochloride and mebeverine hydrochloride, carvedilol and hydrochlorothiazide) in their tablets. J AOAC Int 93: $1192-1200$

7. Abdelwahab NS (2011) Spectrophotometric methods for simultaneous determination of carvedilol and hydrochlorothiazide in combined dosage form Arabian J Chem.

Table 5: Validation and application of the suggested methods for determination of CARV and HCT in spiked human plasma using ${ }^{3} D,{ }^{4} \mathrm{D}$ and ${ }^{1} \mathrm{DD}$ methods.

methods. HCT is rapidly but-incompletely absorbed after oral administration. Peak plasma concentrations of 0.18 to $0.43 \mu \mathrm{g} \mathrm{ml}^{-1}$ were attained in 2 to $4 \mathrm{~h}$, following a single oral administration of a $50 \mathrm{mg}$ tablet of HCT [16]. The lower concentration of HCT in plasma may be attained by applying a standard addition method.

\section{Conclusion}

The proposed methods $\left({ }^{3} \mathrm{D},{ }^{4} \mathrm{D},{ }^{1} \mathrm{DD}\right)$ used a simple plasma deproteination step instead of extraction. No interferences from endogenous substances were observed in human plasma samples. The three spectrophotometric methods are suitable techniques for the analysis of commercial formulations containing combination of CARV and HCT. The most striking features of the proposed methods are their simplicity, sensitivity, selectivity and rapidity, which render them suitable for routine analysis in control laboratories. The proposed methods permit direct determination of the two drugs in bulk powder or in binary mixtures without previous separations. High percentage recovery shows that the methods are free from the interferences of the commonly used excipients and additives in the formulations of drugs.

\section{References}

1. Paul AI, In Gilman AG, Rall TW, Nies AS, Taylor P (1996) In: Goodman and Gilman. The pharmacological Basis of Therapeutics. (8thedn), Mc Graw Hill, New York: 239

2. Heber ME, Bridgen GS, Caurana MP, Lahiri A, Raftery EB (1987) Carvedilol for
8. Laxman R, Ashish A, Vinay J, Sudhir B, Deepti J (2010) Development and validation of RP-HPLC and ultraviolet spectrophotometric methods for simultaneous determination of spironolactone and torsemide in pharmaceutical dosage form. Int J Res Ayurvenda pharm 1: 459-467.

9. Singh HP, Sharma CS, Ankalgi AD, Agal SK, Ranawat MS (2011) Spectrophotometric methods for simultaneous determination of nitazoxanide and ofloxacin in combined bulk and pharmaceutical formulations. Int J Pharm Tech Res 3: 118-123.

10. O Haver TC, Green GL (1976) Numerical error analysis of derivative

11. Fell AF, Smith G (1982) Higher derivative methods in ultraviolet-visible and infra-red spectrophotometry. Anal Proc 19: 28-33.

12. ICH, Q2 (R1) (2005) Validation of Analytical Procedures, Proceedings of the International Conference on Harmonization, Geneva.

13. Patel LJ, Suhagia BN, Shah PB, Shah RR (2006) RP-HPLC and HPTLC methods for the estimation of carvedilol in bulk and pharmaceutical formulations Indian. J Pharma Sci 68: 790-793.

14. The United States Pharmacopoeia 32, and National Formulary 27 (2009) United States Pharmacopoeial Convention. INC 2: 2566.

15. Randez-Gil F, Daros JA, Salvador A, de la Guardia M (1991) Direct derivative spectrophotometric determination of nitrrazepam and clonazepam in biological fluids. J Pharm Biomed Anal 9: 539-545

16. Clark Index (2004) "Clarke's Analysis of Drugs and Poisons in Pharmaceuticals, Body Fluids and Postmortem Materials". (3rdedn), Pharmaceutical Press London, Chicago 2: 1369. spectrometry for the quantitative analysis of mixtures. Anal Chem 48: 312-318. 